\title{
A NEW VALIDATED SIMULTANEOUS REVERSED-PHASE HIGH-PERFORMANCE LIQUID CHROMATOGRAPHY ASSAY METHOD FOR ESTIMATION OF TWO FLAVONES (BAICALEIN AND CHRYSIN) IN API DRUGS
}

\author{
MADDI SESHARAO, VALLABANENI MADHAVARA0* \\ Department of Organic Chemistry, Bapatla Engineering College (Autonomous) Bapatla, Andhra Pradesh, India. \\ Email: seshubecanu@gmail.com
}

Received: 07 July 2017, Revised and Accepted: 31 October 2017

ABSTRACT

Objective: The scope of the present work is a reversed-phase high-performance liquid chromatography (RP-HPLC) assay method developed for the simultaneous determination of baicalein and Chrysin in API drugs.

Methods: The RP-HPLC method employed a Hypersil BDS C18 reversed-phase column $(150 \times 4.6 \mathrm{~mm} \times 5.0 \mu \mathrm{m})$ with an isocratic mixture of water and acetonitrile in the ratio of $55: 45 ; \mathrm{v} / \mathrm{v}$ as the mobile phase. The column temperature was kept at $25^{\circ} \mathrm{C}$. The flow rate was $1.0 \mathrm{~mL} / \mathrm{min}$, and detection was by means of a photodiode array detector at wavelength of $268 \mathrm{~nm}$ and validated for various parameters such as specificity, system suitability, method precision, linearity, accuracy, solution stability, ruggedness, and robustness.

Results: The system suitability parameters were evaluated from standard chromatograms by calculating the \% relative standard deviation (RSD) from six replicate injections for baicalein and Chrysin peak areas. The \% RSD for the peak area of the principal peak from six replicate injections of each standard solution was $<2.0 \%$. The linearity and correlation coefficient of baicalein and Chrysin was found to be 0.999 . Method precision was performed, and \% RSD from six different preparations for baicalein and Chrysin were found to be $<2.0$. The $\%$ recovery for each level was found to be the range of $98.0-102 \%$. In ruggedness and robustness, the \% RSD of the peak area of all peaks for six replicate injections should be not more than 2.0 .

Conclusion: Hence, the chromatographic assay method developed for baicalein and chrysin is said to be rapid, simple, specific, sensitive, precise, accurate, and reliable that can be effectively applied for routine analysis in research institutions, quality control department in industries, approved testing laboratories, bio-pharmaceutics, and bio-equivalence studies and in clinical pharmacokinetic studies.

Keywords: Baicalein, Chrysin, Reversed-phase high-performance liquid chromatography, Method development, Validation

(c) 2018 The Authors. Published by Innovare Academic Sciences Pvt Ltd. This is an open access article under the CC BY license (http://creativecommons. org/licenses/by/4. 0/) DOI: http://dx.doi.org/10.22159/ajpcr.2018.v11i1.21174

\section{INTRODUCTION}

Flavonoids are a family of polyphenolic compounds synthesized by plants with a similar structure and are divided into subclasses, including anthocyanidins, flavanols, flavanones, flavonols, flavones, and isoflavones. Several beneficial properties have been attributed to these dietary compounds, including antioxidant, anti-inflammatory, and anticarcinogenic effects.

Baicalein chemically known as 5, 6, 7,-trihydroxyflavone, with molecular formula $\mathrm{C}_{15} \mathrm{H}_{10} \mathrm{O}_{5}$, whose molecular weight is $270.24 \mathrm{~g} / \mathrm{mol}$. Baicalein is a flavone, a type of polyphenolic flavonoid, that is extracted from the roots of Scutellaria baicalensis and Scutellaria lateriflora that have a wide variety of health benefits. It is primarily used in Asian countries as an herbal supplement. Baicalein inhibits the action potential of the neurons that raise anxiety. In mice, baicalein produces anxietylowering effects without causing drowsiness or muscle relaxation [1-2]. Baicalein was shown in Figs. 1 and 2.

In developing countries, where the challenge of substandard drugs and drug counterfeiting is enormous, there is the need for methods which are accurate, cost-effective, easy to use, rapid, and require the use of non-sophisticated equipment to facilitate easy identification and quantitation of the active components in multicomponent drugs and formulations. The main objective of this work is to develop and validate a new, simple, accurate, linear, precise, specific, robust, rugged, and cost-effective reversed-phase high-performance liquid chromatography (RP-HPLC) assay method for simultaneous estimation of baicalein and chrysin. Literature survey revealed that several methods were used to analysis of baicalein and chrysin, in formulations, human urine, and human blood serum. These methods include simultaneous estimation of assay in a single method. The aim of this study is performing very simple method in terms of mobile phase and program to analyze baicalein and chrysin in API drugs.

\section{METHODS}

Instrument

Chromatographic separation was performed with HPLC having waters, equipped with 2695 with photodiode array detector (PDA). Chromatograms and data were recorded by means of Empower software.

Chemicals and reagents

Acetonitrile and methanol were procured from the Merck.

Stationary phase

Analytical column: Hypersil BDS C18 column $(150 \mathrm{~mm} \times 4.6 \mathrm{~mm}$ $\times 5.0 \mu \mathrm{m}$ ) was used.

\section{Mobile phase}

Mix the 55 volumes of water and 45 volumes of acetonitrile.

Diluent

Mix the 60 volumes of acetonitrile and 40 volumes of methanol. 


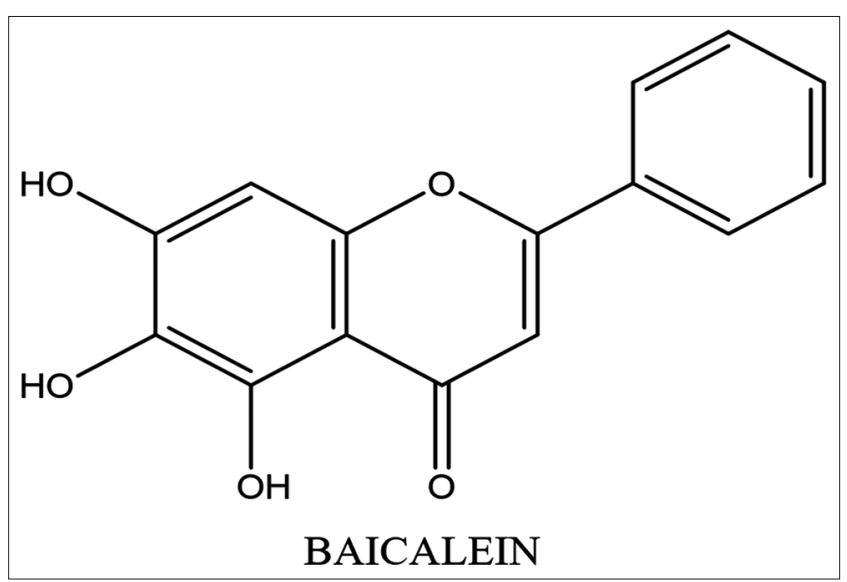

Fig. 1: Baicalein

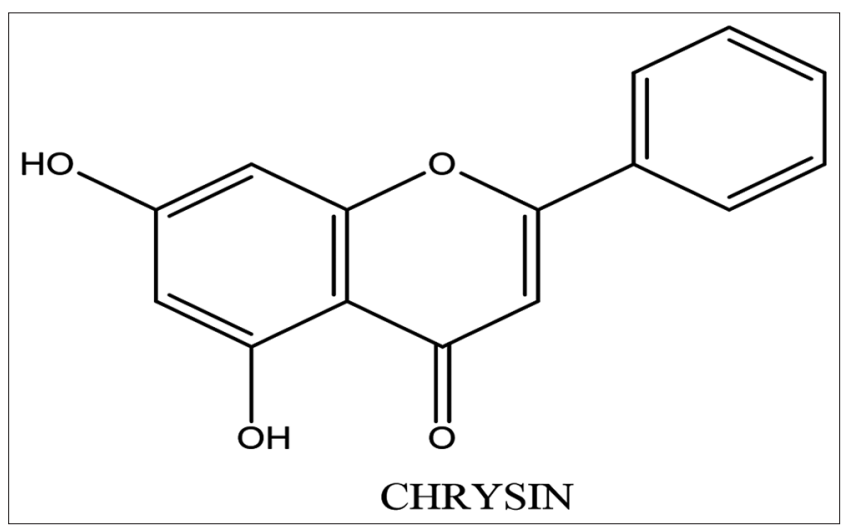

Fig. 2: Chrysin

\section{Preparation of standard solution}

About $50 \mathrm{mg}$ of each baicalein and chrysin standards were accurately weighed and transferred in a $50 \mathrm{~mL}$ volumetric flask and dissolved in $30 \mathrm{~mL}$ of diluent and made up with diluent. Take $5 \mathrm{~mL}$ of this solution into $100 \mathrm{~mL}$ of diluent was added. Finally, to obtained $0.05 \mathrm{mg} / \mathrm{mL}$ of baicalein and chrysin standard solution.

\section{Preparation of sample solution}

About $50 \mathrm{mg}$ of each baicalein and chrysin samples were accurately weighed transferred in a $50 \mathrm{~mL}$ volumetric flask and dissolved in $30 \mathrm{~mL}$ of diluent and made up with diluent. Take $5 \mathrm{~mL}$ of this solution into $100 \mathrm{~mL}$ of diluent was added to obtain $0.05 \mathrm{mg} / \mathrm{mL}$ of baicalein and chrysin sample solution.

\section{Chromatographic conditions}

The established chromatographic conditions included a mobile phase of water and acetonitrile (55:45 v/v), a hypersil BDSC18 (150×4.6 mm $\times 5 \mu \mathrm{m}$,) stationary phase, and a flow rate of $1 \mathrm{~mL} / \mathrm{min}$. The wavelength of detection was $268 \mathrm{~nm}$, and mode of elution was isocratic. The temperature was kept constant at $25^{\circ} \mathrm{C}$. Injection volume was $20 \mu$. These conditions gave the best resolution of peaks and separation of components.

\section{Method validation}

A full method validation was performed according to guidelines set by the USFDA and ICH [3-5]. The validation of this procedure was performed to evaluate the method in terms of specificity, system suitability, method precision, linearity, accuracy, solution stability, ruggedness, and robustness [6-7].

\section{Specificity}

Equal volume $(20 \mu \mathrm{l})$ of standard preparation and test preparation were separately injected into the chromatograph. Chromatograms were recorded and measured the responses for major peaks.

\section{System suitability}

Equal volume $(20 \mu \mathrm{l})$ of standard preparation was injected into the chromatograph. Chromatograms were recorded and measured the responses for major peaks.

\section{Method precision}

Equal volume $(20 \mu \mathrm{l})$ of six different standard preparation solutions was injected into the chromatograph. Chromatograms were recorded and measured the responses for major peaks.

\section{Linearity}

Equal volume $(20 \mu \mathrm{l})$ of standard preparation was injected at different concentration of $25-150 \%$ into the chromatograph. Chromatograms were recorded and measured the responses for major peaks.

\section{Accuracy}

It was obtained by recovery studying using the standard addition method, and equal volume $(20 \mu \mathrm{l})$ of accuracy at $50 \%, 100 \%$, and $150 \%$ solutions was injected into the chromatograph. Chromatograms were recorded and measured the responses for major peaks.

\section{Solution stability}

It was obtained by solution stability study using the standard prepared solution. $20 \mu \mathrm{l}$ of initial, after $4 \mathrm{~h}, 6 \mathrm{~h}, 8 \mathrm{~h}, 12 \mathrm{~h}$, and $24 \mathrm{~h}$ sample solutions were injected into the chromatograph. Chromatograms were recorded and measured the responses for major peaks.

\section{Ruggedness}

Equal volume of standard preparation was injected into the chromatograph by two different analysts in two different days. Chromatograms were recorded and measured the responses for major peaks.

\section{Robustness}

It is a method parameter study. Equal volume of standard preparation was injected into the chromatograph by the change of two method parameters. Chromatograms were recorded and measured the responses for major peaks.

\section{RESULTS AND DISCUSSION}

Method development and optimization mobile phase selection Preliminary studies with several solvent systems were performed to select the most effective solvent system for the separation of the flavones. The selection of these solvents as possible mobile phases depended on factors such as cost of solvents, polarities of solvents and that of the analytes of interest, and the solubility of the analytes. Solvents such as water methanol, acetonitrile, as well as combinations of these solvents were tried. The mobile phase of water and acetonitrile was tried in different proportions. However, an isocratic mixture of water and acetonitrile in the ratio of 55:45; v/v was chosen as the mobile phase because it produced the best resolution of peaks, peak symmetry, and separation of all components within the least retention times. The retention times are $2.42 \mathrm{~min}$ for Baicalein and $4.73 \mathrm{~min}$ for Chrysin.

\section{Stationary phase selection}

The polarities of the analytes of interest were taken into consideration when choosing the stationary phase. As the drug molecules are polar or moderately polar, reversed-phase stationary phases were tried. A Hypersil BDS C18 reversed phase column $(150 \times 4.6 \mathrm{~mm} \times 5.0 \mu \mathrm{m})$ was chosen to reduce the time of interaction between the stationary phase and the analytes. This helped to reduce analysis time as there is reduced affinity of the analytes for the stationary phase and increased interaction of the analytes with the mobile phase.

\section{Wavelength selection}

In simultaneous estimation of two flavones, isobestic wavelength is used. Standard solution of baicalein was prepared by accurately weighed $50.0 \mathrm{mg}$ and transferred into $50 \mathrm{~mL}$ volumetric flask and dissolved in $30 \mathrm{~mL}$ of diluent, and then, makeup to the mark with the 
diluent and prepare $50 \mu \mathrm{g} / \mathrm{mL}$ of solution by diluting $2.5-50 \mathrm{~mL}$ with diluent. Moreover, a standard solution of chrysin was prepared by accurately weighed $50.0 \mathrm{mg}$ and transferred into $50 \mathrm{~mL}$ volumetric flask and dissolved in $30 \mathrm{~mL}$ of diluent, and then, dilute up to the mark with diluent and prepare $50 \mu \mathrm{g} / \mathrm{mL}$ of solution by diluting $2.5-50 \mathrm{~mL}$ with diluent. The wavelength of maximum absorption $\left(\lambda_{\max }\right)$ of the drug of $50 \mu \mathrm{g} / \mathrm{mL}$ solution in diluent was scanned using PDA within the wavelength region of 200-400 $\mathrm{nm}$ against diluent as blank. The $\lambda_{\mathrm{max}}$ was found to be $271 \mathrm{~nm}$ for Baicalein, $263 \mathrm{~nm}$ for Chrysin, and finally, $268 \mathrm{~nm}$ was selected for the combination of two flavones, and the peak purity is also passed. Peak purity graph is shown in Fig. 3.

\section{Method validation}

Specificity

Peak purities higher than $99 \%$ were obtained for two flavones in the chromatograms of sample solutions depicting that the method was very specific to the two flavones under consideration. There were no interfering peaks on the retention times of the flavones in the presence of excipients. This was very evident in the chromatograms of the sample (Fig. 4)

\section{System precision}

$0.05 \mathrm{mg} / \mathrm{mL}$ of standard solution was prepared to calculate the precision for the developed method. The prepared solution was injected into injector $(\mathrm{n}=6)$ at the same concentrations and same chromatographic conditions. The chromatograms were recorded. The values are given in Table 1. Relative standard deviation (\% RSD) for the values calculated is $0.32 \%$ for baicalein and $0.31 \%$ for chrysin. Hence, the developed method shows precision. The chromatograms are shown in Fig. 5.

\section{Method precision}

$0.05 \mathrm{mg} / \mathrm{mL}$ of six different standard solutions were prepared to calculate the precision for the developed method. The six prepared solutions were injected into injector $(n=1)$ at thr same concentrations and same chromatographic conditions. The chromatograms were recorded. The values are given in Table 2. \% RSD for the values calculated is $0.60 \%$ for baicalein and $0.33 \%$ for chrysin. Hence, the developed method shows method precision. The chromatograms are shown in Fig. 6.

\section{Linearity}

Regression analysis of the standard calibration graphs was used to determine the linearity of the developed method. The results obtained showed that the method is linear for the two flavones in the range of $12.5-75 \mu \mathrm{g} / \mathrm{mL}$ for baicalein and chrysin, respectively, with their coefficient of correlation $\left(\mathrm{r}^{2}\right)$ all approximately equal to 1.00 $\left(r^{2}=0.999\right)$. The linearity graphs and results are presented in Fig. 7 and Table 3 .

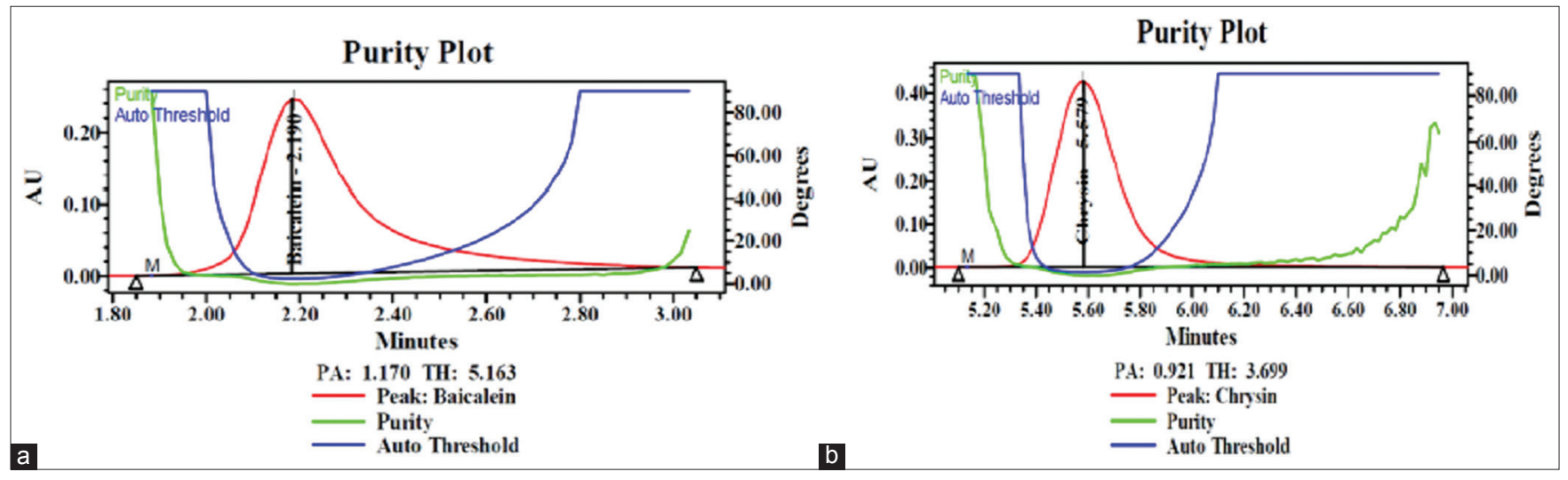

Fig. 3: Peak purity chromatograms of (a) baicalein and (b) chrysin

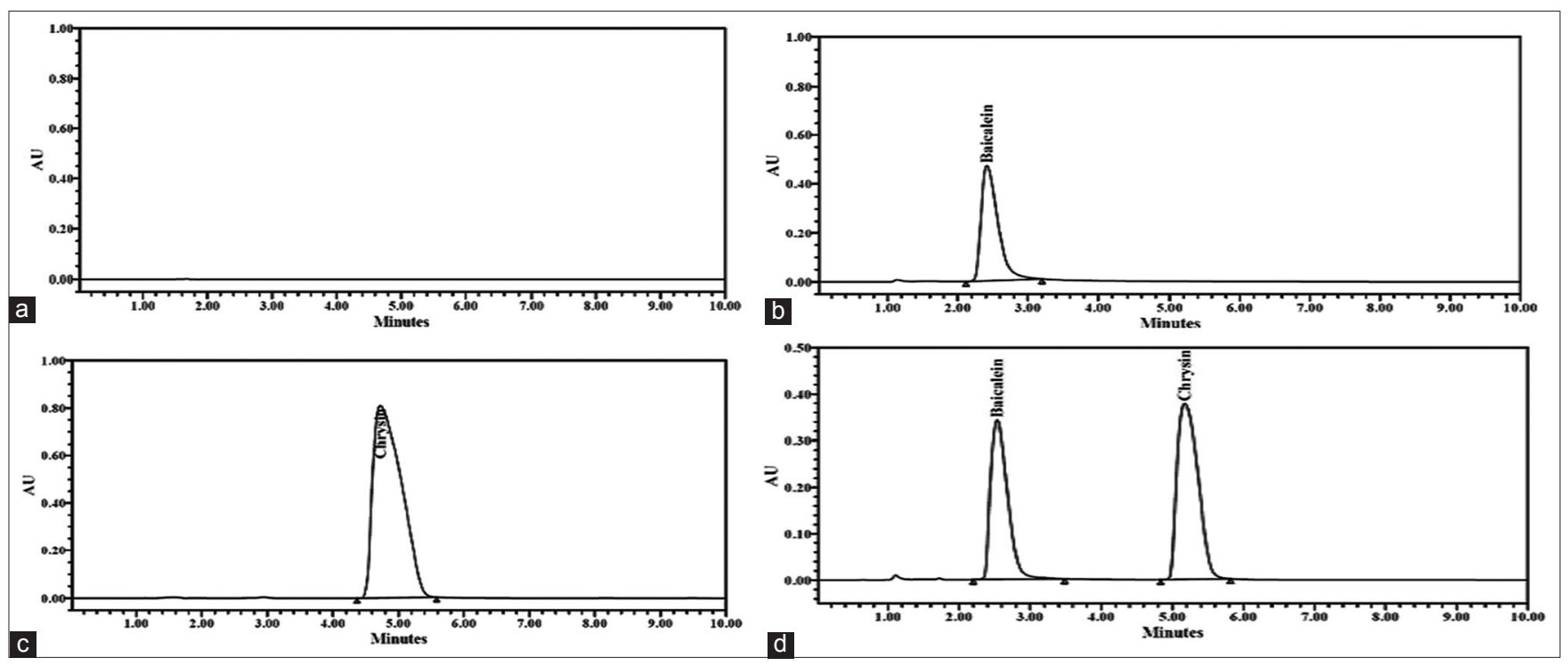

Fig. 4: Specificity chromatograms of (a) blank, (b) baicalein, (c) chrysin, and (d) spiked 
Accuracy

The accuracy of the method was determined by studying recovery at three different concentrations $(50 \%, 100 \%$, and $150 \%)$ for two flavones, by triplicate analysis $(n=3)$. Samples of known concentration (reference standard solutions) were analyzed, and the measured values, from the respective peak areas, were compared with the true values. The recovery was found to be within acceptable range $(100 \pm 2 \%)$, and the $\%$ RSD was also passed for all 9 determinations (NMT 2.0\%). The results are summarized in Table 4.

Table 1: System precision data for baicalein and chrysin

\begin{tabular}{lll}
\hline S. No. & Baicalein & Chrysin \\
\hline 1 & 5576062 & 7747849 \\
2 & 5581329 & 7800040 \\
3 & 5550935 & 7765177 \\
4 & 5578333 & 7748135 \\
5 & 5561463 & 7779667 \\
6 & 5603420 & 7734489 \\
Average area & 5575257 & 7762559 \\
SD & 18011.04 & 24152.63 \\
\% of RSD & 0.32 & 0.31 \\
\hline
\end{tabular}

RSD: Relative standard deviation, SD: Standard deviation

Table 2: Method precision data for baicalein and chrysin

\begin{tabular}{lll}
\hline S. No. & Baicalein & Chrysin \\
\hline Preparation-1 & 5587492 & 7733816 \\
Preparation-2 & 5589526 & 7807818 \\
Preparation-3 & 5573496 & 7750829 \\
Preparation-4 & 5607766 & 7753723 \\
Preparation-5 & 5530749 & 7778764 \\
Preparation-6 & 5630255 & 7758130 \\
Average area & 5586547 & 7763847 \\
SD & 33628.09 & 25932.40 \\
\% of RSD & 0.60 & 0.33 \\
\hline
\end{tabular}

RSD: Relative standard deviation, SD: Standard deviation

Table 3: Linearity data for baicalein and chrysin

\begin{tabular}{lll}
\hline Concentration $(\boldsymbol{\mu g} / \mathbf{m l})$ & Area of baicalein & Area of chrysin \\
\hline $12.5(25)$ & 1695953 & 2478657 \\
$25(50)$ & 3003818 & 4247809 \\
$37.5(75)$ & 4295336 & 5962634 \\
$50(100)$ & 5563238 & 7702486 \\
$62.5(125)$ & 7227209 & 9738116 \\
$75(150)$ & 8386573 & 11080588 \\
Correlation coefficient $\left(\mathrm{r}^{2}\right)$ & 0.999 & 0.999 \\
\hline
\end{tabular}

\section{Solution stability}

Standard and sample solutions of two flavones were stored in a capped volumetric flask on a laboratory bench under normal lighting conditions for initial, 4 h, 6 h, 8 h, 12 h, and 24 h were injected (n=2) into the chromatograph. These results shown to be stable with no significant change in progesterone concentration during this period. The $\%$ assay of each period should not differ by more than $\pm 0.5 \%$ to the initial assay value. The chromatograms and data are summarized in Fig. 8 and Table 5.

\section{Ruggedness}

Ruggedness of the method was evaluated by performing the sample analysis in six replicates using different analyst on different days. System suitability of the standard solution was checked at each day and each analyst and data were found to be within the acceptable range. The \% RSD values was $<2.0 \%$. This indicates that the method adopted is rugged. The data of ruggedness were summarized in Table 6.

\section{Robustness}

Robustness of the method was investigated by varying the instrumental conditions such as the mobile phase change ( \pm 2.0 volumes) and column flow change ( $\pm 0.1 \mathrm{~mL} / \mathrm{min}$ ), system suitability of the standard solution was checked at each variable condition, and data were found to be within the acceptable range (\% RSD NMT2.0). The data of ruggedness were summarized in Table 7.

\section{Batch analysis}

Prepared about $0.05 \mathrm{mg} / \mathrm{mL}$ of baicalein and chrysin standard solution and $0.05 \mathrm{mg} / \mathrm{mL}$ of three different batches of baicalein and chrysin API sample solution. The \% assay of each batch on as it is basis should be within the limit (98.0-102\%). The data are summarized in Table 8.

\section{CONCLUSION}

An accurate, simple, linear, specific, and precise RP-HPLC assay method to estimate the simultaneous assay quantification of baicalein and chrysin has been developed and validated. In this method, solid buffers are not used. Hence, the column goes for the longer periods. The simplicity of the method allows for application in laboratories that lack sophisticated analytical instruments such as LC-MS and GC-MS. These methods are complicated, costly, and rather time consuming than a simple HPLC-PDA method. The assay was linear from $12.5 \mu \mathrm{g} / \mathrm{mL}$ to $75 \mu \mathrm{g} / \mathrm{mL}$. The recovery was found to be within acceptable range $(100 \pm 2 \%)$, and the \%RSD was NMT $2.0 \%$ for all 9 determinations, as per ICH guideline. Thus, the proposed HPLC assay method can be successfully applied for the routine quality control analysis of baicalein and chrysin, and, also useful for formulation analysis of baicalein and chrysin.

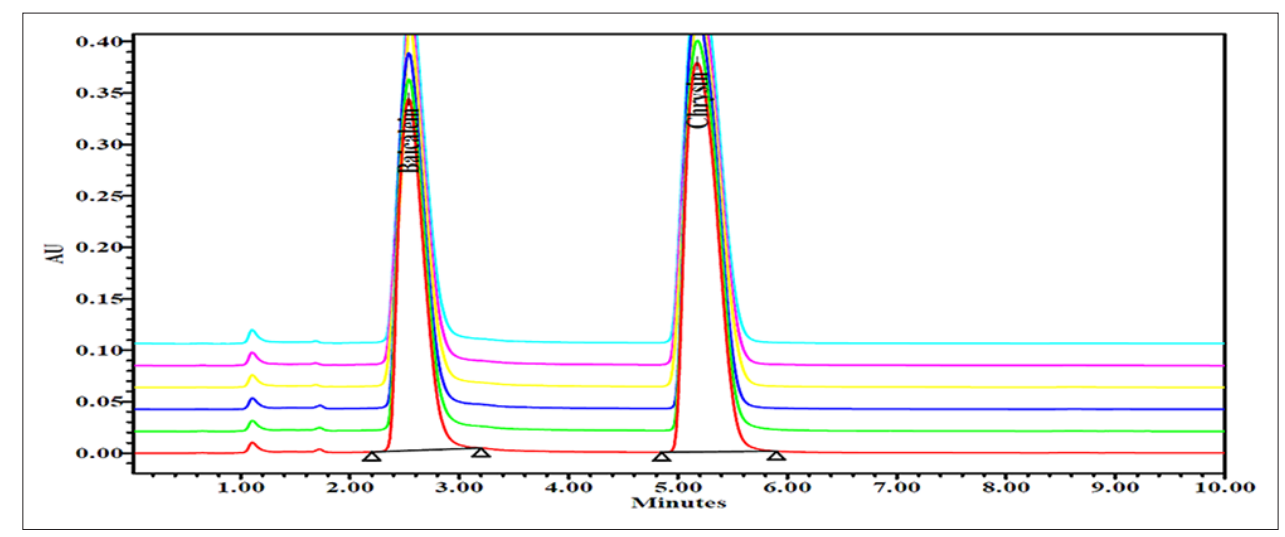

Fig. 5: System precision \% relative standard deviation chromatogram of baicalein and chrysin 


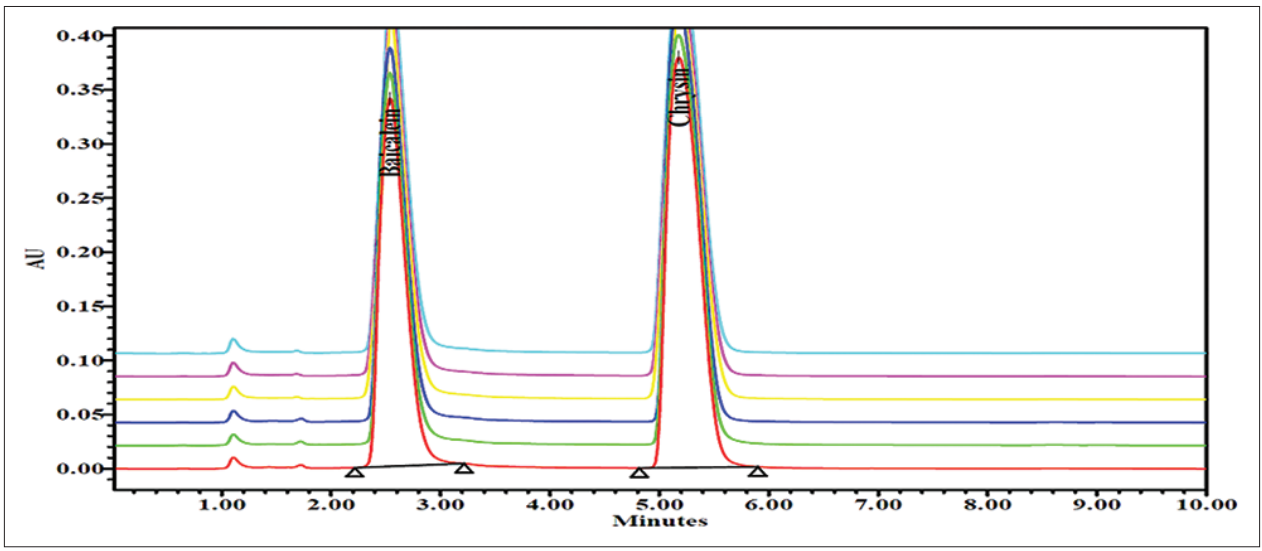

Fig. 6: Method precision\% relative standard deviation chromatogram of baicalein and chrysin

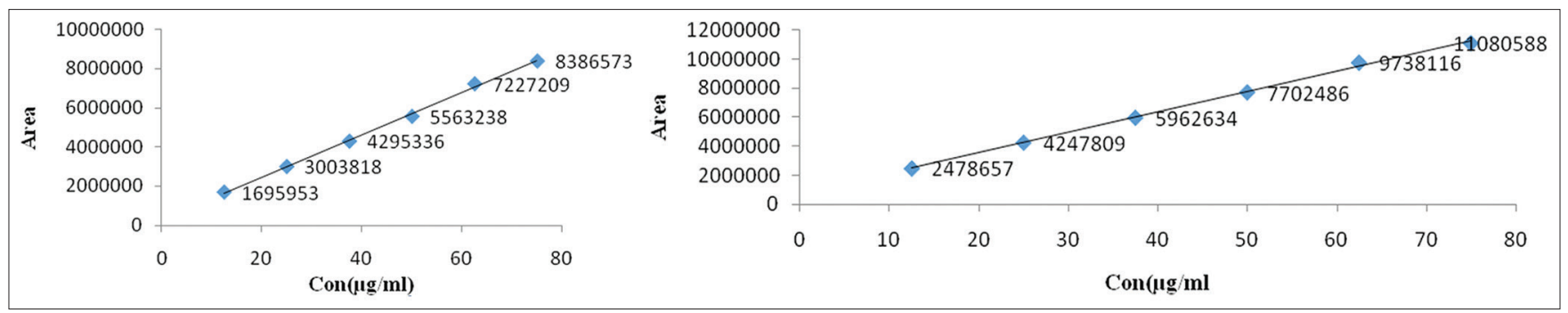

Fig. 7: Linearity graph for baicalein and chrysin

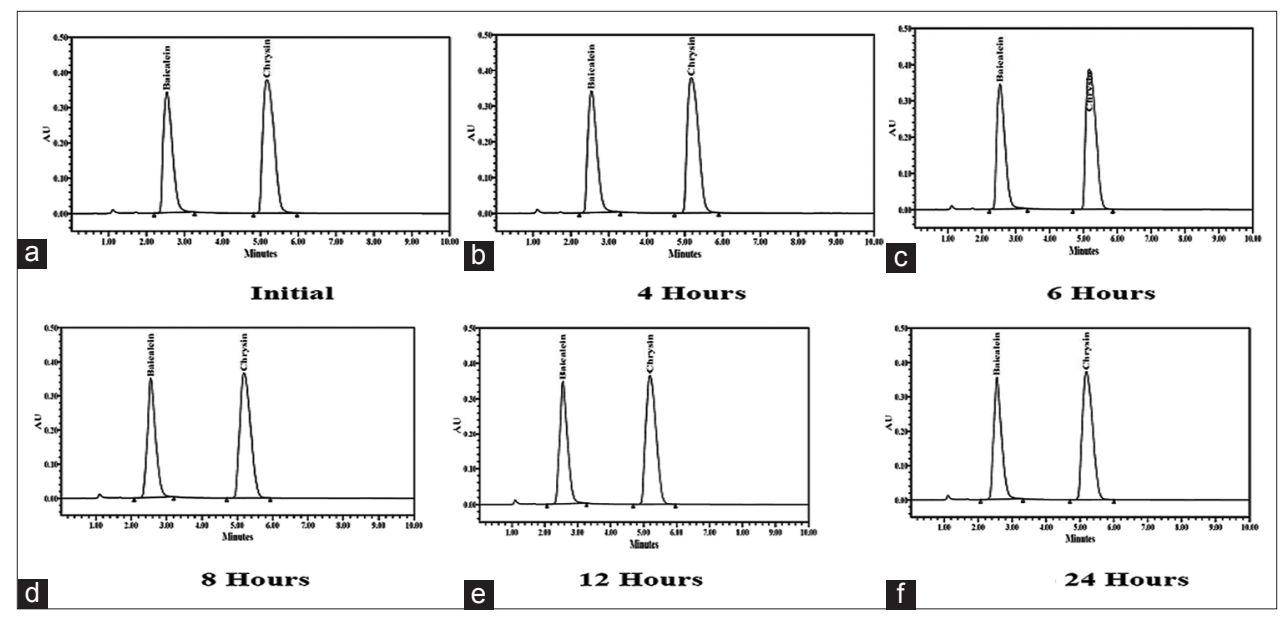

Fig. 8: Solution stability graphs for baicalein and chrysin, (a) initial, (b) 4 h, (c) 6 h, (d) 8 h, (e) 12 h, and (f) 24 h

Table 4: Accuracy data for baicalein and chrysin

\begin{tabular}{|c|c|c|}
\hline Accuracy \% level & $\%$ Recovery of baicalein & \% Recovery of chrysin \\
\hline \multicolumn{3}{|l|}{ Accuracy - 50\% } \\
\hline Run-1 & 99.99 & 101.72 \\
\hline Run-2 & 100.52 & 101.74 \\
\hline Run-3 & 101.14 & 101.76 \\
\hline \multicolumn{3}{|l|}{ Accuracy - $100 \%$} \\
\hline Run-1 & 99.43 & 99.16 \\
\hline Run-2 & 99.44 & 99.17 \\
\hline Run-3 & 98.97 & 99.14 \\
\hline \multicolumn{3}{|l|}{ Accuracy - 100\% } \\
\hline Run-1 & 99.51 & 98.34 \\
\hline Run-2 & 99.57 & 98.46 \\
\hline Run-3 & 99.53 & 98.47 \\
\hline Average for $9 \%$ Rec. determinations & 99.79 & 99.77 \\
\hline SD for $9 \%$ Rec. determinations & 0.66 & 1.51 \\
\hline$\%$ RSD for $9 \%$ Rec. determinations & 0.66 & 0.46 \\
\hline
\end{tabular}


Table 5: Solution stability data for baicalein and chrysin

\begin{tabular}{lllllll}
\hline Flavones & Standard area & Initial & $\mathbf{4 ~ S h}$ & $\mathbf{6} \mathbf{h}$ & $\mathbf{8} \mathbf{h}$ & $\mathbf{1 2} \mathbf{h}$ \\
\hline Baicalein & 5575257 & 5604818 & 5625919 & 5669094 & 5574019 & 5551400 \\
\% Assay & - & 99.71 & 99.89 & 99.83 & 99.46 & 99.45 \\
Chrysin & 7762559 & 7759663 & 7744563 & 7777477 & 7757702 & 7771151 \\
\% Assay & - & 99.76 & 99.65 & 99.87 & 99.43 & 99.80 \\
\hline
\end{tabular}

Table 6: Ruggedness data for baicSalein and chrysin

\begin{tabular}{|c|c|c|c|c|c|c|c|c|}
\hline \multirow{3}{*}{$\begin{array}{l}\text { Name of } \\
\text { flavone }\end{array}$} & \multicolumn{3}{|l|}{ Day-1 } & \multicolumn{3}{|l|}{ Day-2 } & \multirow{3}{*}{$\begin{array}{l}\text { Analyst-1 } \\
\text { \%RSD } \\
\text { Day-1 and } 2\end{array}$} & \multirow{3}{*}{$\begin{array}{l}\text { Analyst-2 } \\
\text { \% RSD } \\
\text { Day-1 and } 2\end{array}$} \\
\hline & $\%$ RSD & \% RSD & \% RSD & \% RSD & $\%$ RSD & $\%$ RSD & & \\
\hline & Analyst-1 & Analyst-2 & Analyst- 1 and 2 & Analyst-1 & Analyst-2 & Analyst- 1 and 2 & & \\
\hline Baicalein & 0.72 & 0.84 & 0.80 & 0.89 & 0.74 & 0.75 & 0.68 & 0.83 \\
\hline Chrysin & 0.30 & 0.42 & 0.30 & 0.38 & 0.30 & 0.35 & 0.26 & 0.38 \\
\hline
\end{tabular}

Table 7: Robustness data for baicalein and chrysin

\begin{tabular}{|c|c|c|c|c|}
\hline \multirow[t]{2}{*}{ Parameter } & \multicolumn{2}{|l|}{ Baicalein } & \multicolumn{2}{|l|}{ Chrysin } \\
\hline & $\begin{array}{l}\text { Average } \\
\text { area }(n=6)\end{array}$ & $\%$ RSD & $\begin{array}{l}\text { Average } \\
\text { area }(n=6)\end{array}$ & $\%$ RSD \\
\hline \multicolumn{5}{|c|}{ Flow rate $(\mathrm{mL} / \mathrm{min})$} \\
\hline 0.9 & 5935407 & 0.41 & 8512705 & 0.04 \\
\hline 1.0 & 5575257 & 0.32 & 7762559 & 0.31 \\
\hline 1.1 & 5051099 & 0.63 & 7057308 & 0.04 \\
\hline $53: 47$ & 5528230 & 0.44 & 7826856 & 0.06 \\
\hline $55: 45$ & 5575257 & 0.32 & 7762559 & 0.31 \\
\hline $57: 43$ & 5492531 & 0.18 & 7847002 & 0.04 \\
\hline
\end{tabular}

Table 8: Batch analysis data for baicalein and chrysin

\begin{tabular}{lllll}
\hline Name of the flavone & STD average area $(\mathbf{n = 6})$ & Batch-I average area $(\mathbf{n = 2})$ & Batch-II average area $(\mathbf{n}=\mathbf{2})$ & Batch-III average area $(\mathbf{n}=\mathbf{2})$ \\
\hline Baicalein & 5615042 & 5611330 & 5528445 & 5569198 \\
\% Assay & - & 99.48 & 99.19 & 99.52 \\
Chrysin & 7738375 & 7721735 & 7702151 & 7677324 \\
\% Assay & - & 99.59 & 99.77 & 99.29 \\
\hline
\end{tabular}

\section{ACKNOWLEDGMENT}

The author expresses sincere thanks to the Principal and Head of the Chemistry Department, BEC College, for excellent guidance and encouragement.

\section{REFERENCES}

1. Wang F, Xu Z, Ren L, Tsang SY, Xue H. GABA A receptor subtype selectivity underlying selective anxiolytic effect of baicalin. Neuropharmacology 2008;55:1231-7.

2. Anandhi R, Annadurai T, Anitha TS, Muralidharan AR, Najmunnisha K, Nachiappan V, et al. Antihypercholesterolemic and antioxidative effects of an extract of the oyster mushroom, Pleurotus ostreatus, and its major constituent, chrysin, in triton WR-1339-induced hypercholesterolemic rats. J Physiol Biochem 2013;69:313-23.
3. ICH, Q2A, Harmonized Tripartite Guideline, Validation of analytical Procedure Methodology. Geneva: IFPMA, Proceedings of the International Conference on Harmonization; 1994.

4. ICH Harmonized Tripartite Guideline. Validation of Analytical Procedures: Text and Methodology; 2005.

5. ICH Q2B, Harmonized Triplicate Guideline. Validation of Analytical Procedure Methodology. Geneva: IFPMA, Proceeding of the International Conference on Harmonization; 1996.

6. Bhamre PR, Rajput SJ. Development of HPLC and chemometric assisted spectrophotometric method for the simultaneous determination of five active ingradients in cough and cold tablets and their application to dissolution study. Int J Pharm Pharm Sci 2016;8:33-40.

7. Rajoriya V, Soni A, Kashaw V. Method development and validation of dissolving tablet of ramipril by HPLC method. Int J Pharm Pharm Sci 2016;8:127-31. 